waste chips. Nos. $1-8$ and 11 are such supposable instances. Both parts of No. 8 were picked up. Few entire or finished implements occur, as they would not be left in these places unless lost. Nos. 9 and 10 are complete; Nos. 12-14, roughly chipped and supposably unfinished.

Proximity to the supply of chert has doubtless determined this common occurrence of chippings in the sandy stretches near the lake. There is no evidence at hand of greater antiquity than the Indian.

Evanston, III., Feb. 15. W. A. Phillips.

\section{Illusive memory.}

For some time past, I have been investigating a curious psychical or psycho-pathological experience which is alluded to by many writers upon psychology, and is not infrequently met with in general literature. It is that vague sentiment of familiarity we sometimes have upon entering a new experience, best expressed in the words, 'I have seen or known all this before.' It has been explained by various writers, upon two widely different theories. The first is, that this 'double perception,' 'double thinking,' 'double presentation,' as it has been variously named, arises from the dual structure of the brain, resulting in cases of imperfectly correlated action in two images or impressions not absolutely simultaneous: the latter, therefore, is a repetition of the former, and gives rise to a sentiment that it has passed through the mind at some indefinite previous time. This theory, it will be observed, is a physiological one. The other theory is, that the phenomenon is a purely psychical one; that the false or illusory memory (Erinnerungstäuschung, Sander) has a real basis in some actual past presentation which is identical, or closely similar, with the present one; or in some past images of the waking imagination, or dream-life, that, although these cannot be recalled into consciousness, they are sufficient to give us the conviction that the present event is the repetition of a former one - why, or how, we do not know. There are several cases upon record, where this sentiment has assumed a pathological character, and become a continual delusion, attending every experience.

Two years ago, in the hope of obtaining more information, I distributed a question upon the subject among a large number of persons, principally collegestudents. It may now be given in somewhat amplified form, as follows:-

Have you come suddenly upon an entirely new scene, and, while certain of its novelty, felt inwardly that you had seen it before - with a conviction that you were revisiting a dimly familiar locality? Mention, if you can, an instance or two in which this has occurred. Has any satisfactory explanation of this experience ever suggested itself to you? How frequent is the experience in your case? Was it more frequent in childhood than at present? How soon do you usually become conscious of the deception? Does it occur more frequently in connection with some kinds of experience than with others?

A quantity of material upon this subject has already been collected in this and other ways, which I hope to publish in a review article in April. In the mean while, any information bearing upon this question will be of great assistance and value to me.

Princeton, N.Y., Feb. 23.

HENRY F. OsBorn.

\section{Ripple-marks in limestone.}

The alternating limestones, shales, and sandstones of the upper coal-measures of Kansas are well ex- posed along the ridges and water-courses near Eureka. Some of the limestone is thin-bedded, apparently due to interlaminated sheets of argillaceous material. The layers of limestone, however, seem to contain little foreign matter, certainly not more than the Trenton limestones (Buff) of Wisconsin and Minnesota. The organic remains consist largely of crinoid columns, shells of brachiopods and lamellibranchs, and a few gastropod shells and cup corals. Nearly every layer of limestone shows these remains in great abundance firmly bound together by the highly crystalline matrix.

I have beell thus particular in describing the limestone, that the conditions which made the following feature possible may be understood. Some six or eight slabs of this limestone in one of our sidewalks are clearly and distinctly ripple-marked. This is the first instance of the kind that has fallen under my observation during ten years of state and private work in nearly as many states of the Union.

The occurrence of ripple-marks in calcareous mud containing the remains of deep-sea, clear-water animals, and interlaminated with argillaceous mud, is a combination not quite in accordance with the teachings of our text-books in geology.

Eureka, Kan., Feb. 23.

L. C. Wooster.

\section{A novel magnetic engine.}

It is a well-known fact that iron, when heated to a red heat, ceases to be magnetic; so that an armature, after being heated to redness, may be removed from its magnet by the expenditure of only a small fraction of the energy which is developed by the attraction of the same armature when it has cooled.

Manifestly this fact might be employed in the construction of a motor, which, while of no practical value, is of theoretical interest, in which a permanent magnet should act as the direct motive force. This has been done in the following manner. In the figure, $a b c$ represents a ring thirteen centimetres in diameter, and supported horizontally upon radial arms and an axis of some non-magnetic metal. This ring is made of one or more

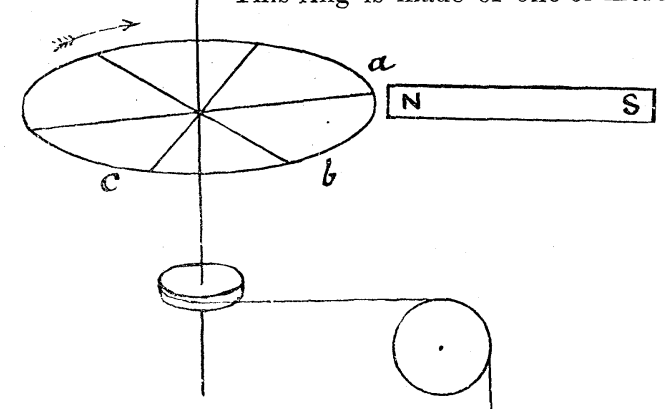

turns of iron wire of about a millimetre diameter. $N S$ is either a permanent or an electro magnet. The axis is furnished with a driving-pulley, cord, and weight, as shown in the figure.

That part of the ring which lies between $a$ and $c$ is heated to bright redness by means of two or three Bunsen burners. The magnet then exerts a preponderating attraction upon the farther or cool side of the ring, and the latter revolves as indicated by the 